\title{
Cirit Atma Tekniği ve Biyomekaniksel Açıdan Değerlendirilmesi
}

\author{
Sena ÇARIKCI ${ }^{1}$ (D) , Kübra TUZ ${ }^{2}$ (D) , Bahar ANAFOROĞLU KÜLÜNKOĞLU ${ }^{3}$ \\ ${ }^{1}$ Ankara Yıldııım Beyazıt Üniversitesi Sağık Bilimleri Enstitüsü, ANKARA \\ 2 Ondokuz Mayıs Üniversitesi Havza Meslek Yüksekokulu, SAMSUN \\ ${ }^{3}$ Ankara Yıldırım Beyazıt Üniversitesi, Fizyoterapi ve Rehabilitasyon Bölümü, ANKARA
}

Derleme

DOI:10.53434/gbesbd. 878826

Öz

$\mathrm{Bu}$ derleme, cirit atma tekniğinin biyomekaniksel açıdan değerlendirilmesi amacıyla hazırlanmıştır. Cirit atma teknikleri genellikle beş bileşenden oluşur. Cirit omzun üzerinde yere paralel taşınır. Sporcu maksimum hıza ulaşmak için, firlatma hareketine geçmeden önce bir hız kazanma koşusu yapar. 10-15 adımlık hızlanmanın sonuna doğru sporcu ciridi geri çekmeye başlar. Koşunun ikinci bölümü çapraz adımlarla alınır. Çapraz adımlardan hemen sonra sporcuyu atış aşamasına geçiren geçiş adımı atılır. Ardından iletim fazına geçilir. İletim fazı sağ el ile atış yapan sporcu için sol ayak dokunuşu ile başlar ve ciridin elden serbest kalmasiyla sona erer. Disk atma, çekiç atma ve gülle atma gibi esas olarak rotasyonel tekniklerin aksine, cirit atma ağırlıklı olarak doğrusal bir olaydır. Cirit atışının hızlanma yolunun doğrusal olması, onu diğer atma sporlarından ayırmaktadır. Cirit atışının performansını etkileyen parametreler olarak, boy ve kol uzunluğu ile omuz genişliği gösterilebilir. Ciridin ağırlığının fazla olması yaralanma riskini arttırabilmektedir. Fırlatma sporlarında özellikle omuz ve dirsek üzerine ciddi stresler binmekte olup bu bölgelerin akut ve aşırı kullanım yaralanmalarına sık rastlanılmaktadır.

Anahtar sözcükler: Cirit atma, Atış biyomekaniği, Atletizm 


\title{
Javelin Throw Technique and Its Evaluation in Biomechanical Terms
}

\begin{abstract}
This review has been prepared to evaluate the javelin throw technique in terms of biomechanics. Javelin is a field sport is made to achieve the longest shot. For the javelin throw, the vechile, the body of which is made of metal or a different homogeneous material and whose tip is sharpened, is used. Javelin throwing techniques usually consists of five components. The javelin is carried parallel to the ground over the shoulder. In order to reach maximum speed, the athlete performs a speed-up run before taking the throwing motion. Towards the end of the 10-15 step acceleration, the athlete begins to pull the javelin back. The second part is taken in diagonal steps. Immediately after the crossover steps, the transition step that takes the athlete to the shooting stage is taken. Then the transmission phase is passed. The delivery phase starts with the touch of the left foot for the right-handed athlete and ends with the javelin releasing from the hand. Unlike mainly rotational techniques such as discus throwing, hammer throwing and shot put, javelin throwing is a predominantly linear event. The fact that the javelin throw's acceleration path is linear distinguishes it from other throwing sports. Height and arm length and shoulder width can be shown as parameters that affect the performance of the javelin throw. The heavy weight of the javelin can increase the risk of injury. In throwing sports, serious stresses are placed on the shoulders and elbows, and acute and overuse injuries of these areas are common.
\end{abstract}

Keywords: Javelin throw, Throwing biomechanics, Athletics

\section{Giriş}

Cirit atma, en uzun atışı başarmak amacıyla yapılan bir saha sporudur. Bu derleme, cirit atme tekniğinin biyomekaniksel açıdan değerlendirilmesi amacıyla hazırlanmıştır.

\section{Cirit Atma}

Atletizmin çabuk kuvvet gerektiren branşlarından atma branşları altında yer alan cirit atma sporu, en uzun atışı başarmak amacıyla yapılan bir saha sporudur. Cirit atma sporu, atış sahası, hızlanma şekli ve atış materyalinin farklı olması yönüyle atletizmin diğer atma branşlarından farklılık gösterir. Fırlatma eyleminin dönme hareketi içerdiği disklerin aksine cirit atma, baş üstünden atışı içerir. Çekiç, disk, gülle atma branşları bir çember alanının içinde gerçekleştirilirken; cirit atma sporu hızlanma koşusu ve atış alanını içeren özel bir sahada yapılmaktadır (Demirci, 2003; İşler, 1997).

Uluslararası Atletizm Federasyonları Birliği yarıșma kuralları (WA, 2020a) uyarınca cirit atışı için, gövdesi metal ya da farklı bir homojen malzemeden yapılmış, ucu sivrileșerek sonlanan cirit aracı kullanılmaktadır. Cirit yapısal olarak kafa, gövde ve tutamak olmak üzere üç kısımdan oluşmaktadır. Erkek sporcular 800 gr ağırlığında ve 2.60-2.70 m uzunluğunda, kadın sporcular 600 gr ağırlığında ve 2.20-2.30 m uzunluğunda cirit kullanırlar (Leigh, 2012; WA, 2020). Ciridin ağırlığı yaşla birlikte azalır. 49 yaşına kadar olan erkekler için cirit 800 gr ağırlığındayken, ciridin ağırlığı her on yılda bir düşer; 70-79 yaş arası erkekler 500 gr, 80 yaş ve üstü erkekler 400 gr cirit atarlar. Ciridin ağırlığı sporcunun yaşı ve cinsiyetine göre farklılık göstermektedir. Adolesan grup 
kızlarda ciridin ağırlığı; 12-13 yaş için 400 gr, 14-17 yaş için 500 gr, 18-20 yaş için 600 gr iken adolesan grup erkeklerde; 12-13 yaş için 600 gr, 14-17 yaş için 700 gr, 18-20 yaş için ise 800 gr dır. Ciridin ağırlığı yaşla birlikte azalır. 49 yaşına kadar olan erkekler için cirit 800 gr ağırlığındayken, ciridin ağırlığı her on yılda bir düşer, 70-79 yaş arası erkekler 500 gr cirit kullanır ve 80 yaş ve üstü sporcular 400 gr cirit atarlar. 49 yaşına kadar olan kadınlar için ise cirit 600 gr ağırlığındayken, 50-74 yaş arası kadınlar 500 gr, 75 yaş üstü kadınlar 400 gr cirit atarlar (Ganse ve Degens, 2018; Athletics Direct, 2016).

Cirit atma sektörü; 30 m-36.5 m uzunluğundaki atış yeri, 4 m genişliğindeki koşu alanı ve bu koşu alanına atış yönüne göre dik olarak konumlanan $8 \mathrm{~m}$ yarıçapında bir kavisten meydana gelir. Bu kavis, koşu yolunun her iki yanından dişa doğru 1,5 m uzunluğunda doğrusal olarak $28.96^{\circ}$ açllmaktadır (Demirci, 2003; WA, 2020). (Şekil 1).

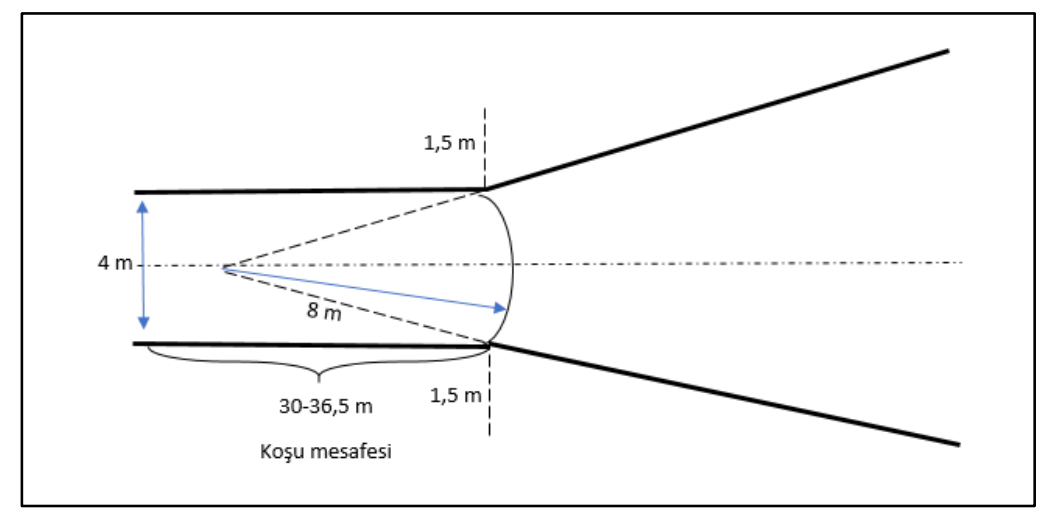

Şekil 1. Cirit atma sektörü

Cirit atmada kıdemli erkek sporcularda dünya rekoru $98.48 \mathrm{~m}$ lik atış ile Jan Železný'e aitken (Çekya, 25 Mayıs 1996 Jena, Almanya); kıdemli kadın sporcularda Dünya rekoru 72.28 m lik atış ile Barbora Špotáková 'a aittir (Çekya 13 Eylül 2008 Dünya Atletizm Finali Stuttgart, Almanya). 20 yaş altı erkek sporcularda Neeraj Chopra 86.48 m' lik atış ile; kadın sporcularda ise Yulenmis Aguılar 63.86 m lik atış ile Dünya rekoruna sahiptir (WA, 2020b).

\section{Cirit Atma Kuralları}

Cirit atma sporunda World Athletics (WA) tarafından belirlenen aşağıdaki kurallar uygulanmaktadır (WA, 2020a):

- Atış sırasında cirit, orta kısmı olan tutamak üzerinden tutulmalı, atış kolunun üst kısmından yani omuz üzerinden atılmalıdır.

- Cirit atışı sırasında parmakların tutuş pozisyonunu etkileyecek herhangi bir ekipman kullanımına izin verilmez. 
- Atış için hakem onayından sonra 1 dakikalık süre verilir; eğer bu süre içinde atış gerçekleşmezse atış hakkı kaybedilir.

- Sporcuların 3 atış hakkı bulunmaktadır.

- Atış sonunda ciridin önce ucunun yerle temas ettiği noktadan atış mesafesi hesaplanır. Ciridin ucu yere temas etmezse atış hakkı geçersiz sayılır.

- Cirit atılıncaya kadar sporcuların sırtının atış yönüne dönmesine izin verilmez.

- Cirit yerle temas edene kadar sporcuların koşu alanını terk etmesine izin verilmez.

- Atış sırasında koşu alanının sonundaki faul çizgisini geçen sporcuların ve ciridi atış açısının dışına isabet ettiren sporcuların atışları geçerli sayılmaz.

\section{Cirit Atma Tekniğinde Hareket Bölümleri}

Cirit atma tekniği diğer atış sporlarına göre oldukça farklı ve yoğun antrenman gerektiren bir tekniktir (Young, 2001). Bir cirit sporcusu; doğru kontrol, gelişmiş koordinasyon, çok eklemli hareketler barındıran karmaşık bir teknik gerçekleştirir. Cirit sporcusu, ciridi yüksek atış hızlarına çıkarabilmek için büyük kuvvetler geliştirmek durumundadır (Morriss ve Bartlett, 1996). Ayrıntılı teknikler sporcular arasında farklılık gösterse de cirit atma tekniği genellikle beş evreden oluşur. Bunlar; cirit tutma ve taşıma, hız kazanma koşusu (ciridi geriye alma, çapraz adım), geçiş adımı ve atış aşamasına geliş, iletim fazı, atış ve atış sonrasıdır (Leigh, 2012; Morriss ve Bartlett, 1996).

\section{Cirit Tutma ve Taşıma}

Cirit, sert ama rahat bir tutuşla, yere paralel olarak firlatma omzunun üzerinde taşınır. Cirit tutma ve taşıma aşaması, sporcunun gücünü cirit atma sırasında yönlendirir. Sporcu ciridini avuç içi yukarıda, dirseği yaklaşık 90 derece fleksiyon ve omzu yaklaşık 90 derece abdüksiyonda olacak şekilde omzunun üzerinde taşır (Leigh, 2012; Morriss ve Bartlett, 1996). Ciridin uç kısmı atış yönüne doğru ve yere paralel olarak konumlanır. Üç tip cirit tutuşu bulunmaktır. Bunlar; Amerikan tutuşu, Fin tutuşu ve çatal tutuşudur. Amerikan tutuşunda cirit başparmak ve işaret parmağı arasında kavranır, Fin tutuşunda cirit baş parmak ile orta parmak arasında kavranır ve işaret parmağı ciridin kuyruğuna doğru yönlendirilebilir veya ciridin etrafına sarılabilir, çatal tutuşunda cirit işaret parmağı ile orta parmak arasında kavrama yapılır (Stander, 2015). Cirit kavrama kuvveti için yapılan ağırlıklı parmak egzersizlerinin atış rekor seviyesini olumlu yönde etkilediği ortaya konmuştur (Abd-El Ga ve Hassan 2016).

\section{Hız Kazanma Koşusu}

Sporcu, ciridi bırakma sırasında maksimum hıza ulaşmak için, fırlatma hareketine geçmeden önce bir hız kazanma koșusu yapar. Sporcu, maksimum hıza ulaşmak amacıyla yaptığı koşuyu doğrusal ivmelenme, çapraz adım alma ve geçiş adımı olarak üç farklı 
aşamada gerçekleștirir. Hız kazanma koşusunun büyük bir bölümü doğrusal ivmelenmeyle gerçekleștirilir. Koşunun sonuna doğru omuz ve gövdenin posteriora pozisyonlanması başlar (Demirci, 2003). Koşu mesafesi her sporcuya göre farklılık göstermekle birlikte 10-15 adımı içermektedir ve yaklaşık olarak 30 m'dir (Leigh, 2012; Murakami, Tanabe, Ishikawa ve Ito, 2017).

Hız kazanma koşusu sporcunun, ciridin momentumunu artırmasına olanak sağlar (Carr ve Carr, 1997). Sporcu öne doğru bakacak ve omuz çizgisi ve kalça çizgisi firlatma yönüne yaklaşık olarak dik ve ayakları firlatma yönüne bakacak şekilde fırlatma sahasına doğru nispeten dik bir pozisyonda koşar (Leigh, 2012; Morriss ve Bartlett, 1996).

\section{Ciridi Geriye Alma}

Sporcu, 10-15 adımlık hızlanmanın sonuna doğru ciridi geri çekmeye başlar. Atış kolu tam dirsek ekstansiyonda omuz ekseni doğrultusunda posteriora alınır, destek kolu atış kolunu anteriora doğru ilerleyerek çaprazlar ve sporcunun omuz çizgisi firlatma yönünün çizgisine yaklaşık olarak paralel hale gelmeye başlar (Morriss ve Bartlett, 1996). Avuç içinin yönü yukarı dönük konumdadır ve atış kolu ile birlikte posteriora hareket eder (Tekil, 1984).

\section{Çapraz Adım}

Hız kazanma koşusunun ikinci bölümü çapraz adımlarla alınır. Çapraz adımlar sporcunun kalça ekseninin firlatma yönüne 45 derece ile 90 derece arasında döndürüldüğü bir tür yanal koşu türüdür (Leigh, 2012). Sporcu hız kazanma koşusunun büyük kısmını (2/3'ünü) doğrusal olarak koştuktan hemen sonra çapraz adımlara geçiş yapılır. Çapraz adım sayısı her sporcuya göre değişiklik göstermekte ve 3, 5 ya da 7 adım olarak uygulanabilmektedir (Demirci, 2003). Çapraz adımların başlangıcı ile gövdenin üst bölümü de posteriora doğru esner. Sporcunun başı atış yönüne doğru bakar. Çapraz adımlarla ileriye doğru koşmak, cirit atışı sırasında kuvvet uygulayabilmek için büyük bir düzlemin oluşumuna fırsat verir. Son çapraz adım, ağırlık merkezinin cirit atma işlemine hızlı bir şekilde devam etmesini sağlamak için sporcuyu konumlandıran adımdır (Morriss ve Bartlett, 1996).

Çapraz adımlar sırasında ciridi geriye alma işlemi, bir ritim içerisinde yapılmalı böylece hız artışına engel olmadan doğru hareket akışı bütünlük halinde sağlanmalıdır (Işsler, 1997). Bu sırada kalça ve dizlerdeki fleksiyon hareketi nedeniyle ağırlık merkezi bir miktar aşağıya iner (Demirci, 2003).

\section{Geçiş Adımı ve Atış Aşamasına Geliş}

Geçiş adımı çapraz adımlardan hemen sonra atılan ve sporcuyu atış aşamasına geçiren adımdır. Geçiş adımı çapraz adımlara kıyasla daha geniştir. Sağ el ile atış yapan sporcu çapraz adımları tamamladığında, sol ayağı önde, sağ ayağı arkada olacak şekilde konumlanır. Bu adımın ortalama uzunluğu $1.74 \mathrm{~m}$ dir (Pavlovic ve diğerleri, 2020). Ardından sağ ayak ileriye doğru geniş bir adım alır. Sağ ayağın yerle teması 
gerçekleşmeden, sol ayak havada çaprazlama yaparak sağ ayağın önüne geçer. Hareketin bu aşamasında her iki ayağın anlık olarak yer ile teması kesilir. Son durumda sol ayak önde, să̆ ayak arkada, geniş bir adım halinde konumlanır (Demirci, 2003). Bu adımın ortalama uzunluğu $2.26 \mathrm{~m}$ dir (Pavlovic ve diğ., 2020).

Geçiş adımının tek destek aşaması, sağ el ile atış yapan sporcu için son çapraz adımın sağ ayak dokunuşu ile başlar ve sonraki sol ayak teması ile biter. Geçiş adımının amacı, sporcuyu firlatma hareketini gerçekleştirmek için optimum konuma yerleştirmektir. Geçiş adımı sırasında, sporcunun sağ ayağı önce yere temas ederken, sol bacağı atış yönünde uzanır. Sporcunun sol ayağı, sol kalçası ve sağ omzunu birleştiren yaklaşık düz bir çizgi ile geriye doğru bir gövde eğimi olmalıdır. Sporcunun sağ kalçası, diz ve ayak bileği eklemleri tek destek sırasında vücudunun sağ ayağı üzerinde dönmesini kolaylaştırmak için fleksiyondadır. Bu, frenlemeyi en aza indirerek cirit atılana kadar daha yüksek hız ve momentumunun korunmasına izin verir (Leigh, 2012).

\section{İletim Fazı}

İletim fazı, sağ el ile atış yapan sporcu için sol ayak dokunuşu ile başlar ve ciridin elden serbest kalmasıyla sona erer. İletim fazının amacı, ciridin en uygun yönde maksimum hızda atılması için son bir ivme vermektir. Sol ayak önde sağ ayak arkada ve $45^{\circ}$ eksternal rotasyonda konumlanır (Demirci, 2003). Böylece sporcunun kalça çizgisini, fırlatma yönüne dik hale getirmek için sağ kalçasını fırlatma yönüne doğru rotasyona alması kolaylaşır. Bu kalça rotasyonunu üst gövdenin öne doğru rotasyonu izler, sağ omzunu fırlatma yönüne doğru hareket ettirir ve omuz çizgisini furlatma yönüne dik olarak getirir. $\mathrm{Bu}$ kalça ve omuz rotasyonunu takiben, üst ekstremite eklemleri doğrusal hızı artırmak için sırayla hareket eder. Eklem hareketleri önce omuz eklemi horizontal adduksiyonu ve iç rotasyondur, bunu dirsek eklemi ekstansiyonu, ardından el bileği fleksiyonu ve son olarak ciridin atışı izler (Leigh, 2012; Morriss ve Bartlett, 1996).

\section{Atış ve Atış Sonrası}

Cirit atışı, vücudun aniden durmasına ve enerjinin vücuttan ve cirite aktarılmasına bir tepki kuvveti olarak meydana gelir. Sağ el ile atış yapan sporcunun sol ayağı yere temas ettiğinde bir destek noktası oluşur ve ciridin enerjisini aktarmaya başlar. Sol taraf, sağ tarafın hızlanacağı bir dayanak noktası olacak kadar sağlam olmalıdır. Geçiş adımı sırasında sol ayak topuğunun yere dayanması ile birlikte atış evresi başlar. Kalçanın öne yer değiștirmesini sağ bacağın ekstansiyonu takip eder (Demirci, 2003).

Atış sonrası, özellikle omuz yaralanmaları için (bankart lezyonu, humerus başı anterior subluksasyon-luksasyonu vb.) risk içeren bir aşamadır. Sporcu ciridi attıktan hemen sonra, kalan momentumu dağıtmak ve tamamen durmak için birkaç adım daha atar. Böylelikle doğru teknikle atış gerçekleştirildiğinde fırlatma sırasında omuza binen stres azaltılmış olur. Sporcu faul çizgisinin arkasında atışı tamamlamış olmalıdır (Leigh, 2012). 


\section{Cirit Atış Biyomekaniği}

Disk atma, çekiç atma ve gülle atma gibi esas olarak rotasyonel tekniklerin aksine, cirit atma tekniği, kinematik olarak doğrusal gerçekleştirilen bir atma tekniğidir. Bununla birlikte, cirit atmanın önemli bir rotasyonel bileșeni de vardır. Sporcular, koşmanın son birkaç adımında firlatma yönüne doğru yanal koşarlar ve fırlatma yönüne bakarken cirit atmadan önce vücutlarını döndürürler (Leigh, 2012). Açısal hareketin çoğunun meydana geldiği atış sırasında cirit önemli bir hız kazanır (Best ve Bartlett, 1986). Bu nedenle cirit atma, maksimum bırakma hızını elde etmek için yüksek hızlarda gerçekleștirilmesi gereken hem üç boyutlu doğrusal hem de rotasyonel bileşenler içerir (Leigh, 2012). Cirit atışında atış açısı, hızı, yüksekliği ve aerodinamik etkenler gibi birçok biyomekanik unsur atış mesafesini etkilemektedir (Jalalabadi, Mohammadi ve, 2019; Leigh, 2012).

Havanın cirit yüzeyine göre hareketi, cirit üzerinde bir yüzey kuvvetinin etki etmesine neden olur. Bu yüzey kuvveti aerodinamik bir kuvvettir. Kaldırma ve sürtünme kuvveti olmak üzere iki bileşeni vardır. Kaldırma kuvveti, ciridin yüzeyine dik olarak hareket eden ve yerçekimi etkilerine karşı koyan genel olarak yukarı doğru hareket etme eğiliminde olan bileşendir. Sürtünme kuvveti, ciridin yüzeyine paralel hareket eden ve ciridin yavaşlamasına neden olan bileşendir (Best ve Bartlett, 1988; Hubbard, 1984). Bir ciridin uçuşunun aerodinamik bileşeni, aerodinamik kuvvetin büyüklüğüne ve yönüne, bu kuvvetin basınç merkezine ve ciridin kütle merkezine bağlıdır (Hubbard, 1984). Aerodinamik bileșenin cirit uçuşunu oldukça etkilediği görüldüğünden ciridin ağırlık merkezi yeni kurallarda $4 \mathrm{~cm}$ ileri kaydırılmıştır. Ek olarak; ağırlık merkezinin önündeki yüzey alanı azalırken, kütle merkezinin arkasındaki yüzey alanı artar. Bu önlemlerin etkisi ciridin tıpkı bir okun uçuşu gibi bağıll rüzgâra dönüşen havada daha kararlı olmasıdır (Looijen, 2020).

Cirit atma tekniğinin zirve noktası, ciridi serbest bırakma yani atıştır. Cirit atıldıktan sonra, atılan mesafeyi artırmak için cirit üzerinde başka bir kontrol uygulanamaz. Bu nedenle firlatma tekniğinin amacı, cirit tarafından kat edilen en büyük mesafeyi elde etmek için atış değişkenlerini optimize etmektir. Atış hızı, ciridin kütle merkezinin atış sırasındaki hız vektörünün mutlak büyüklüğü olarak tanımlanmıştır (Leigh, 2012).

Atış hızının, hız kazanma koşusu hızının ve iletim fazı sırasında cirit hızındaki kazancın toplamı olduğu gösterilmiştir (Best ve Bartlett, 1986). Erkek cirit sporcularının 80 metreden fazla mesafelere ulaşması için $28,5 \mathrm{~m} / \mathrm{s}$ 'yi aşan atış hızlarının gerekli olduğu ve kadın cirit sporcularının 60 metreden fazla mesafelere ulaşması için $25 \mathrm{~m} / \mathrm{s}$ 'nin üzerindeki atış hızlarının gerekli olduğu öne sürülmüștür. Atış hızının atış mesafesi ile güçlü bir şekilde pozitif korelasyon gösterdiği gösterilmiştir (Best ve Bartlett, 1986; Pavlovic, 2020; Rich, Whiting, McCoy, Gregor ve Ward, 1985). Atış hızı, performansı yöneten ve atılan mesafeyi sporcular arasında farklılaştıran en önemli faktördür (Best ve Bartlett, 1986; Rich ve diğ., 1985). 
Hız kazanma koşusu aracılığıyla elde edilen ciridin atış hızını artırmanın birincil yöntemi, cirit üzerine kuvvet uygulamaktır (Bartlett, 1983). Önerilen bu yöntemde, geriye doğru gövde eğimi artırılır (Kunz ve Kaufman, 1980). Geriye doğru gövde eğimini artırmak, ciridin kat ettiği yatay ve dikey mesafeyi artırabilmektedir.

Gövde eğim açısı firlatma performansı ve atış mesafesi ile önemli bir korelasyon göstermektedir (Chow, Kuenster ve Lim, 2003; Kunz ve Kaufman, 1980). Atış hızını artırmak için önerilen başka bir yöntem, vücut bölümlerinin ivmelenmesinin zamanlamasıdır. Her bir vücut bölümünün maksimum açısal hızını, gövdenin orta hattından sağ ele doğru bir sırayla kendisinden önceki parçanın maksimum açısal hızına sırayla ekleyerek, zincirdeki son halkada daha büyük bir açısal momentum üretilecektir. $\mathrm{Bu}$ yöntem, cirite hızı aktarmak için mevcut olan açısal momentumu artırarak cirit üzerine uygulanan kuvveti artırabilmektedir (Leigh, 2012).

Cirit atış performansını etkileyen parametrelerden bir diğeri olan atış açısı, ciridin atış sırasındaki kütle merkezinin hız vektörünün yönü ile yatay düzlem arasındaki açı olarak tanımlanır. Cirit atma için en uygun atış açısı yaklaşık 36,5 derece olarak bildirilmiştir (Best ve Bartlett, 1988). World Athletics (WA) oyunlarındaki cirit atışlarında $89 \mathrm{~m}$ cirit hareket mesafesi için $31^{\circ}-37^{\circ}$ atış açısı gözlenmiştir (Campos, Brizuela ve Ramón, 2004). Bununla birlikte artmış dirsek ekstansiyon açısının atış hızını artırdığı ve cirit atış mesafesini iyileştirdiği ortaya konmuştur. Azalmış dirsek ekstansiyonunun ise, ciridin yükselmesine neden olduğu belirtilmiştir. İlgili çalışmada elit atıcılarda dirsek eklem açısı $158.4^{\circ}$ ile $166.7^{\circ}$ arasında saptanmıştır (Chen, Chou, Lo, Chang ve Chang, 2020).

Atış yüksekliği, ciridin atış sırasındaki kütle merkezinin dikey konumu olarak tanımlanır ve atış biyomekanikleri arasında yer alır. Atış yüksekliğindeki artış, atış mesafesinde bir artışa neden olmaktadır, ancak atış yüksekliğinin arttırılması tekniği değiştirebilmektedir. $\mathrm{Bu}$ nedenle, atış yüksekliğinin tekniği değiştirmeden mümkün olduğu kadar yüksek olması için bu değișkenin maksimize edilmesinden ziyade optimize edilmesi gerekebilir. Atış yüksekliğindeki maksimum değişiklik için atış mesafesinde 0.35 metrelik bir artıştan söz edilmektedir (Miller ve Munro, 1983) bu durum atış yüksekliğinin, atış mesafesine etkisi en az olan değișken olduğunu düşündürmektedir (Leigh, 2012).

\section{Tekniğin Cirit Atma Performansına Etkisi}

Cirit atmada atış yolu boyunca kazanılmış olan hızın cirite aktarılması gereklidir. Cirit atışının performansını etkileyen parametreler olarak, boy ve kol uzunluğu ile omuz genişliği gösterilebilir (Kale, 2006). Diğer fırlatma sporlarında olduğu gibi cirit atma performansı da hız, açı ve yükseklik değerlerinden etkilenir. Bunun yanı sıra cirit uçuşunun aerodinamiğini etkileyen faktörler de önemlidir. $\mathrm{Bu}$ faktörler arasında sporcular arasındaki performans farkının birincil belirleyicisi atış hızıdır (Bartlett ve Best, 1988). 
Cirit atışıyla ilgili biyomekanik analizlerin yapıldığı çalışmalar mevcuttur. Bu çalışmaların çoğu, performansla ilgili çeşitli faktörlerin kinetik analizlerine yoğunlaşmıştır (Fleisig ve Escamilla, 1996; Young, 2007). Çalışmalardan alınan öneriler atış tekniğini geliştirmede sporcunun atış hızını arttırmak için kas kuvvetine odaklanması gerektiğini belirtmektedir. Young (2007) yapmış olduğu çalışmada, proksimalden distale ateşleme paternleri ve vücut segmentlerinin aktif hızlanma yavaşlama hareketinin sporcunun başarısını arttırmada önemli olduğunu savunmuştur.

Cirit atma performansı üzerinde eklem ve segment hareketlerinin sıralamasının da etkili olduğu düşünülmektedir. Elit cirit sporcularında proksimalden distale doğru eklem merkezinde maksimum doğrusal hızlarda ilerlemeler kaydedilmektedir (Antti, Komi, Korjus, Navarro ve Gregor, 1994). Yapılan bir çalışmada cirit sporcularında kol eklem merkezinde, maksimum doğrusal hız uzun mesafelerde tutarlıken kısa mesafelerde tutarsız bulunmuştur (Whiting ve diğ., 1991). Bunun yanı sıra yapılan bir çalışmada cirit atışında eklem açısal hareketlerinin başlangıcının, proksimalden distale bir sıralamada olması gerekmediği belirtilmiştir. Aynı zamanda kadın ve erkek cirit sporcularının üst ve alt ekstremitede farklı açısal hareketler kullandıkları belirtilmiştir (Liu, Leigh ve Yu, 2010). Bu farklılığın sebepleri olarak sporcuların fiziksel özelliklerinin yanı sıra atışta kullanılan cirit kütlelerinin aynı olmaması gösterilmiştir. Cirit atış performansını geliştirmede cinsiyet farklılığı göz önünde bulundurulması gereken noktalardan biri olarak ifade edilmiştir (Liu, Leigh ve Yu, 2014).

Cirit atışının beyzbol atışıyla ortak özellikler taşıdığı düşünülmektedir. Cirit atışındaki kinetik zincir aktivasyon modeli beyzbol sporcusunun modeline benzer ve adım, pelvis rotasyonu, üst gövde rotasyonu, dirsek ekstansiyonu, omuz internal rotasyonu ve bilek fleksiyonu gibi hareketler içerir (Bartlett ve Best, 1988). Cirit atışının, yaklaşma koșusu ve çapraz adımlamayı takiben beyzbol atışına benzer nitelikte olması durumdan yola çıkarak cirit ve beyzbol sporcularının karşılaştırıldığı çalışmalar mevcuttur. Bunlardan biri de Lin, Cheng, Hung ve Lee (2016) tarafından yapılan çalışma olup iki sporcu grubunda denge karşılaştırılmıştır. Dinamik denge açısından anlamlı düzeyde fark bulunmazken; statik dengede gözler açık durumda cirit sporcuları daha başarılı olmuştur.

\section{Cirit Sporu Yaralanma Mekanizmaları}

Fırlatma sporları içerisinde en ciddi baş üstü sporu cirittir. Diğer fırlatma hareketlerinde olduğu gibi cirit atmada da büyük kuvvet uygulanmasına bağlı olarak, üst ekstremitedeki birden fazla eklemde stres meydana gelir. Bu stres, cirit sporcularında akut ve aşırı kullanım yaralanmalarına sebep olabilir. Akut ve aşırı kullanım yaralanmaları uygulama zaman kaybı, rekabet ve finansal yükler nedeniyle ikincil ve dejeneratif yaralanmalara dahi yol açabilir (Andrews ve Fleisig, 1998). Ciridin ağırlığının fazla olması da yaralanma riskini arttırabilmektedir (Auriemma ve De Luigi, 2018).

Fırlatma sporlarında özellikle omuz ve dirsek üzerine ciddi stresler binmekte olup bu bölgelerin akut ve aşırı kullanım yaralanmalarına sık rastlanılmaktadır (Aguinaldo ve 
Chambers, 2009). Bu yaralanmalar içerisinde cirit sporcularında özellikle ulnar kollateral ligament yaralanması ön plana çıkarken ek olarak; SLAP lezyonu, impingement ve rotator cuff yırtıkları dikkat çekmektedir (Leigh, 2012). Bunlar içerisinde ulnar kollateral ligament yaralanması ilk olarak 1946 yılında cirit sporcularında keşfedilerek literatüre kazandırılmıştır (Waris, 1946). Bu patoloji sporcularda özellikle kontrol ve hız anlamında önemli düşüşlere sebep olmakta ve ciddi bir kariyer riski oluşturmaktadır (Leigh, 2012). Dillman tarafından kadavralar üzerinde yapılan bir çalışmada $40 \mathrm{Nm}$ 'lik valgus torkunun ulnar kollateral ligament yaralanmasına sebep olduğu bildirilmiştir (Dillman, 1991). Dirsek valgus torkunun yanı sıra pelvis pozisyonu da ulnar kollateral ligament yaralanması açısından oldukça önemli bir faktördür. Pelvis, görevini yerine getirmede yetersiz kaldığı zaman gövde rotator kas sistemi yerine omuz ve kol, torku meydana getirmek için daha yüksek hızlarda devreye girmek durumunda kalır. $\mathrm{Bu}$ da pelvisin valgus torku üzerinde etkili olduğunu göstermektedir (Aguinaldo, Buttermore ve Chambers, 2007).

Cirit sporcularında dirseğin yanı sıra omuz yaralanmalarına da sık rastlanılmaktadır. $\mathrm{Bu}$ durum baş üstü fırlatma sporlarında artan eklem hareket açıklı̆̆ ihtiyacına bağlanmaktadır (Bechler ve Jobe, 1994). Cirit sporcularında konsantrik dirsek fleksiyonu ve eksantrik dirsek ekstansiyonu, dirsek internal torkunun yansıması olarak bisepsin kuvvetli kasılmasını gerektirir. Biseps tendonunun uzun başı, glenoid labrumun üst kısmında skapulanın supraglenoid tüberkülü ile bağlantılı olduğu için; bisepsin kuvvetli kontraksiyonu, glenoid labrumu koparmak için yeterli kuvvet geliştirebilir (Andrews, Carson ve Mcleod, 1985). Omzun horizontal abdüksiyon ve eksternal rotasyon torkları da glenoid labrum yaralanmalarıyla ilişkilidir (Fleisig, Andrews, Dillman ve Escamilla, 1995). Rotator cuff kas aktivitesi, eksternal rotasyon ve horizontal abdüksiyon torkunu sağlayarak internal rotasyon ve horizontal addüksiyon torkunu etkisiz hale getirir. Bu zit tork eğilimi, fırlatma sırasında oluşan yüksek kuvvetleri dağıtmada da önemlidir (Bechler ve Jobe, 1994).

Fırlatma sporlarında yaralanmayı önlemenin temel taşı uygun tekniği geliştirmek ve sürdürmektir. Cirit aracı ağır olduğu için yeterli tork ve kuvveti üretmek için denge, koordinasyon, esneklik ve zamanlama gereklidir (Meron ve Saint-Phard, 2017). Cirit sporcularında yaralanmaları önlemek açısından dinamik stabilizatörler oldukça önemlidir. Yapılan bir çalışmada 8 haftalık egzersiz programının rotator cuff kuvveti ve atış tekniği üzerine etkileri incelenmiştir. Çalışmanın sonucunda 8 haftalık egzersiz programının anlamlı düzeyde etkili sonuçlar vermesi, çalışmanın uyguladığı programın cirit sporcularında yaralanmaları önlemede kullanılabilecek bir araç olabileceği sonucuna ulaştırmıştır (Kim, Lee, Shin, Kim ve Moo, 2014).

\section{Sonuç}

Cirit atma sporu, atış sahası, hızlanma şekli ve atış materyalinin farklı olması yönüyle ile atletizmin diğer atma branşlarından farklılık göstermektedir. Biyomekaniksel olarak incelendiğinde atışın birçok unsur tarafından etkilendiği görülmektedir. Cirit atışında atış 
açısı, hızı, yüksekliği ve aerodinamik etkenler gibi birçok biyomekanik unsur atış mesafesini etkilemektedir. Cirit atma performansı üzerinde eklem ve segment hareketlerinin sıralamasının da etkili olduğu düşünülmektedir. Diğer fırlatma hareketlerinde olduğu gibi cirit atmada da büyük kuvvet uygulanmasına bağlı olarak, üst ekstremitedeki birden fazla eklemde stres meydana gelir. Bu stres, cirit sporcularında akut ve aşırı kullanım yaralanmalarına sebep olabilir. Cirit biyomekaniği, hem sporcuların performanslarını arttırmak hem de yaralanmaları önlemek açısından oldukça önemlidir.

\section{Çıkar Çatışması}

$\mathrm{Bu}$ makalenin yayınlanmasıyla ilgili yazarlar arasında herhangi bir çıkar çatışması bulunmamaktadır.

\section{Yazar Katkıları}

Araştırma Fikri: SÇ, KT, BAK; Araştırma Tasarımı: SÇ, KT; Verilerin Analizi: BAK; Makale Yazımı: SÇ, KT, BAK; Eleştirel İnceleme: BAK

\section{Yazıșma Adresi (Corresponding Address):}

Uzm. Fzt. Sena ÇARIKCI

Ankara Yıldırım Beyazıt Üniversitesi Sağlık Bilimleri Enstitüsü, ANKARA

Fizyoterapi ve Rehabilitasyon Doktora Programı

ORCID: 0000-0003-0660-377X

E-posta: senacrkc@gmail.com 


\section{Kaynaklar}

1. Abd-El Ga, H. ve Hassan, N. (2016). The effect of weighted finger exercises on the grip strength and the level record for students of the Faculty of Physical Education, Minia University in the javelin throw competition. Assiut Journal of Sport Science and Arts, 316(3), 203-214.

2. Aguinaldo, A. L., Buttermore, J. ve Chambers, H. (2007). Effects of upper trunk rotation on shoulder joint torque among baseball pitchers of various levels. Journal of Applied Biomechanics, 23(1), 42-51.

3. Aguinaldo, A. L. ve Chambers, H. (2009). Correlation of throwing mechanics with elbow valgus load in adult baseball pitchers. The American Journal of Sports Medicine, 37(10), 2043-2048.

4. Andrews, J. R., Carson, W. G. ve Mcleod, W. D. (1985). Glenoid labrum tears related to the long head of the biceps. The American Journal of Sports Medicine, 13(5), 337-341.

5. Andrews,J. R. ve Fleisig, G. S. (1998). Preventing throwing injuries. Journal of Orthopaedic \& Sports Physical Therapy, 27(3), 187-188.

6. Antti, M., Komi, P. V., Korjus, T., Navarro, E. ve Gregor, R. (1994). Body segment contributions to javelin throwing during final thrust phases. Journal of Applied Biomechanics, 10(2), 166-177.

7. Auriemma, M. ve De Luigi, A. J. (2018). Adaptive throwing sports: discus, javelin, shot put, and boccia. A. De Luigi (Ed.), Adaptive sports medicine (S.301-312). Cham: Springer.

8. Athletics Direct: Throwing weight rules per age group (2016, 7 Temmuz). Erişim adresi: https://www.athleticsdirect.co.uk/throwing-weight-rules-1/.

9. Bartlett, R. (1983). Cinematographical analysis of an international javelin thrower. Athletics Coach, 17, 10-19.

10. Bartlett, R. M. ve Best, R. J. (1988). The biomechanics of javelin throwing: a review. Journal of Sports Sciences, 6(1), 1-38.

11. Bechler, J. R. ve Jobe, F. W. (1994). Impingement and instability in the throwing athlete. Operative Techniques in Sports Medicine, 2(2), 106-110.

12. Best, R. ve Bartlett, R. (1986). Javelin release variables and their importance to the performer and coach with special reference to the 1986 new rules javelins. Proceedings of the Sports Biomechanics Study Group, 11.

13. Best, R. ve Bartlett, R. (1988). Computer flight simulation of the men's new rules javelin. Biomechanics XI-B, 588-594.

14. Campos, J., Brizuela, G. ve Ramón, V. (2004). Three-dimensional kinematic analysis of elite javelin throwers at the 1999 IAAF world championships in athletics. New Studies in Athletics, 19(21), 47-57.

15. Carr, G. ve Carr, G. A. (1997). Mechanics of sport: a practitioner's guide. London: Human Kinetics Publishers.

16. Chen, Y., Chou, Y. C., Lo, T. Y., Chang, W. H. ve Chang, J. H. (2020). Kinematics differences between personal best and worst throws in actual javelin competition. International Journal of Performance Analysis in Sport, 20(1), 10-18.

17. Chow, J. W., Kuenster, A. F. ve Lim, Y. T. (2003). Kinematic analysis of javelin throw performed by wheelchair athletes of different functional classes. Journal of Sports Science \& Medicine, 2(2), 36.

18. Dai, B., Mao, M., Garrett, W. E. ve Yu, B. (2015). Biomechanical characteristics of an anterior cruciate ligament injury in javelin throwing. Journal of Sport and Health Scienc, 4(4), 333-340. 
19. Demirci, A. (2003). Atletizm öğretimi atmalar. Ankara: Nobel Yayın Dağıtım.

20. Dillman, C. J. (1991). Valgus extension overload in baseball pitching. Medicine and Science in Sports and Exercise, 23, 153.

21. Fleisig, G. S., Andrews, J. R., Dillman, C. J. ve Escamilla, R. F. (1995). Kinetics of baseball pitching with implications about injury mechanisms. The American Journal of Sports Medicine, 23(2), 233-239.

22. Fleisig, G. S. ve Escamilla, R. F. (1996). Biomechanics of the elbow in the throwing athlete. Operative Techniques in Sports Medicine, 4(2), 62-68.

23. Ganse, B. ve Degens, H. (2018). Accelerated decline in javelin throwing performance in master athletes 70 years and older-do changes in technique play a role. Sports Medicine International Open, 2(3), 79.

24. Hubbard, M. (1984). Optimal javelin trajectories. Journal of Biomechanics, 17(10), 777 787.

25. İşler, M. (1997). Atletizm (koşular-atlamalar-atmalar), teknik, metod, antrenman. Ankara: TUTIBAAY.

26. Jalalabadi, Y., Mohammadi, S. ve Amiri, F. N. (2019). Analyzing, investigating and calculating the optimum mode of the parameters affecting the record of the javelin throw including the initial velocity, initial angle, and initial height of throw. Turkish Journal of Kinesiology, 5(1), 1-14.

27. Kale, G. (2006). Atletizm'in atma branşlarında bazı antropometrik parametrelerle performansın ilişkilendirilmesi (Yüksek Lisans Tezi). Ankara Üniversitesi Sağlık Bilimleri Enstitüsü, Ankara.

28. Kim, H., Lee, Y., Shin, I., Kim, K. ve Moon, J. (2014). Effects of 8 weeks' specific physical training on the rotator cuff muscle strength and technique of javelin throwers. Journal of Physical Therapy Science, 26(10), 1553-1556.

29. Kunz, H. ve Kaufman, D. (1980). Essentials of the javelin throw: a biomechanical analysis. Track and Field Quarterly Review, 80(18-20).

30. Leigh, S. (2012). The influence of technique on throwing performance and injury risk in javelin throwers (Doktora Tezi). Kuzey Karolina Üniversitesi, NC.

31. Lin, W. H., Cheng, J. H., Hung, W. H. ve Lee, A. J. (2016, Temmuz). A Comparison of Balance Control Between Javelin Throwers And Baseball Pitchers. 34. International Conference on Biomechanics in Sports, Taw Japan.

32. Liu, H., Leigh, S. ve Yu, B. (2010). Sequences of upper and lower extremity motions in javelin throwing. Journal of Sports Sciences, 28(13), 1459-1467.

33. Liu, H., Leigh, S. ve Yu, B. (2014). Comparison of sequence of trunk and arm motions between short and long official distance groups in javelin throwing. Sports Biomechanics, 13(1), 17-32.

34. Looijen, T. (2020, 20 Agustos). The design of the PRODON data javelin: Providing performance feedback for indoor javelin throwing. Erişim Adresi: https://repository.tudelft.nl/islandora/object/uuid\%3A52eac21e-6c97-4e91-8a23$9 \mathrm{cbd} 47 \mathrm{fecc} 84$.

35. Meron, A. ve Saint-Phard, D. (2017). Track and field throwing sports: injuries and prevention. Current Sports Medicine Reports, 16(6), 391-396.

36. Miller, D. ve Munro, C. (1983). Javelin position and velocity patterns during final foot plant preceding release. Journal of Human Movement Studies, 9(1), 1-20.

37. Morriss, C. ve Bartlett, R. (1996). Biomechanical factors critical for performance in the men's javelin throw. Sports Medicine, 21(6), 438-446. 
38. Murakami, M., Tanabe, S., Ishikawa, M. ve Ito, A. (2017). The relationship between approach run kinematics and javelin throwing performance. Asian Journal of Coaching Science, 1(1), 1-14.

39. Pavlovic, R., Idrizovic, K., Savic, V., Vrcic, M., Radulovic, N. ve Simeonov, A. (2020). The differences of kinematic parameters javelin throw between male and female finalists world championship (Berlin, 2009-Daegu, 2011). American Journal of Sports Science and Medicine, 8(1), 8-15.

40. Rich, R., Whiting, W., McCoy, R., Gregor, R. ve Ward, P. (1985). Analysis of release parameters in elite javelin throwers. Track Technique, 92, 2932-2934.

41. Stander, R. (2015, 24 Ocak). Athletics Omnibus-Javelin Throw. Erişim Adresi: https://fliphtml5.com/eobp/hrpn/basic.

42. Tekil, N. (1984). Adam Atletizm. İstanbul: Adam Yayıncllı.

43. Waris, W. (1946). Elbow injuries of javelin-throwers. Acta Chirurgica Scandinavica, 93, 563-575.

44. Whiting, W. C., Gregor, R. J. ve Halushka, M. (1991). Body segment and release parameter contributions to new-rules javelin throwing. Journal of Applied Biomechanics, 7(2), 111-124.

45. World Athletics (2020a, 16 Agustos). World athletics constitution \& book of rules. Erişim Adresi: https://www.worldathletics.org/about-iaaf/documents/book-of-rules.

46. World Athletics (2020b, 17 Temmuz). Javelin throw. records by event. Erişim Adresi: https://www.worldathletics.org/records/by-discipline/throws/javelinthrow/outdoor/men.

47. Young, M. (2001). Developing event-specific strength for the javelin throw. Track Coach, 13(154), 4921.

48. Young, M. (2007, 30 0cak). Preparing for the specific neuromuscular and biomechanical demands of the javelin throw. Erişim Adresi:

https://elitetrack.com/article_files/youngjavelin.pdf. 